\title{
Superior vena cava syndrome presenting as position- dependent periorbital oedema
}

\author{
A L Nguyen, ${ }^{1}$ H Belderbos, ${ }^{2}$ J G van Harten, ${ }^{2}$ L Wijne ${ }^{3}$
}

'Department of Dermatology, Leids Universitair Medisch Centrum, Leiden, The Netherlands

${ }^{2}$ Department of Pulmonology, Amphia Ziekenhuis, Breda, The Netherlands

${ }^{3}$ Department of Dermatology, Amphia Ziekenhuis, Breda, The Netherlands

\section{Correspondence to}

LWijne, Iwijne@amphia.nl

Accepted 18 May 2018

\section{DESCRIPTION}

A 54-year-old woman presented to our dermatology clinic with a 2 months history of periorbital oedema, more prominent after lying down in horizontal position. Her face and throat felt swollen. She experienced dyspnoea on exertion, fatigue and had lost $6 \mathrm{~kg}$ of weight. Treatment with antihistamines and oral prednisone were ineffective. She smoked one pack of tobacco per week. Medical history and family history were unremarkable. She did not use any medications. Physical examination revealed prominent periorbital oedema and facial swelling (figure 1). Chest radiograph revealed a pathologically enlarged right hilum, broadened mediastinum and modest pleural effusion (figure 2). Diagnosis of superior vena cava syndrome (SVCS) was made and the patient was referred to the pulmonologist.

Five days later, she presented at the emergency department with haemoptysis and dyspnoea. Physical examination revealed additional distended superficial veins of anterior chest wall and decreased breath sounds over right lung area. CT scan demonstrated a large process in the right hilum with extensive mediastinal lymphadenopathy, almost completely compressing the superior vena cava, with partial atelectasis of right lower lung lobe and extensive pleural effusion (figure 3). Histological biopsy obtained by bronchoscopy revealed small cell lung cancer (SCLC). Positron emission tomography scan was suspect for left adrenal gland metastasis. SVCS was caused by stage IV SCLC, extensive disease. The patient passed away after several lines of therapy (chemotherapy, radiotherapy and study medication) due to progressive adrenal metastasis and symptomatic brain metastasis.

SVCS consists of symptoms and signs resulting from partial or complete obstruction of blood flow within the superior vena cava. Most cases are caused

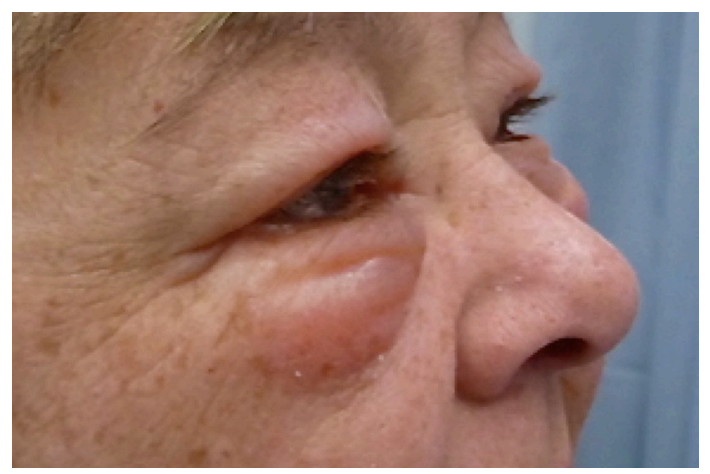

Figure 1 Prominent periorbital oedema and facial swelling after lying down the night before as a presenting symptom of superior vena cava syndrome.

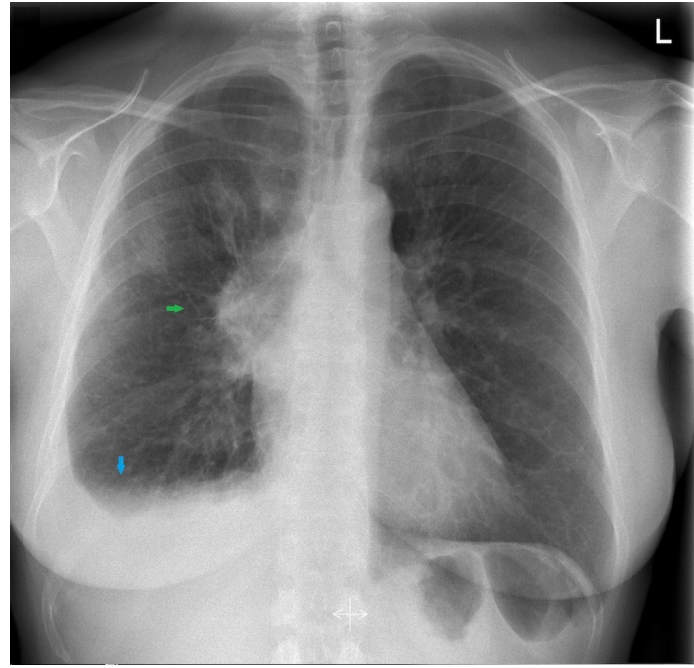

Figure 2 Chest radiography showing a broadened mediastinum with shading of the right hilus (green arrow) and pleural effusion (blue arrow).

by underlying intrathoracic malignancy, of which up to $95 \%$ are due to lung cancer or non-Hodgkin's lymphoma. ${ }^{12}$ This syndrome should be considered in patients presenting with periorbital or facial oedema, aggravated in horizontal position. Other important clinical clues for SVCS include distension of neck and chest wall veins, dyspnoea on exertion, coughing and arm swelling. ${ }^{12}$ Also, the Pemberton's sign is indicative of SVCS when facial congestion and cyanosis occur by elevating both arms. ${ }^{3}$ Diagnosis should be confirmed by CT

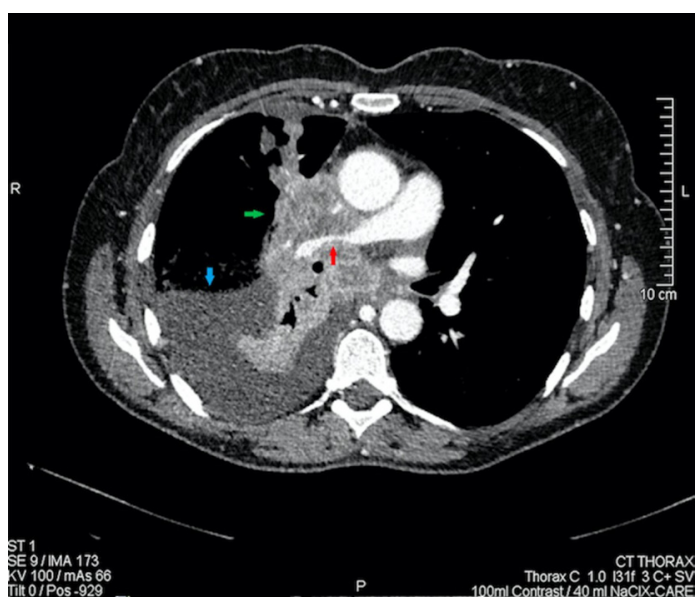

Figure 3 Chest CT demonstrating demonstrated a large infiltrative tumour in the right lower lung lobe (green arrow), almost completely compressing the superior vena cava (red arrow), with extensive lymphadenopathy and pleural effusion (blue arrow). 


\section{Learning points}

- Superior vena cava syndrome (SVCS) should be considered in patients with periorbital or facial oedema, especially when aggravated in horizontal position.

- Early diagnosis of SVCS is crucial in order to alleviate symptoms of obstruction and initiate immediate treatment to prevent life-threatening complications.

and tissue histology in case of suspected malignancy, preferably prior to starting therapy. Treatment and prognosis of SVCS are dependent on its underlying cause. Systemic chemotherapy is the preferred treatment for (extensive-disease) SCLC, which is a chemotherapy-sensitive malignancy responding rapidly (within weeks) to chemotherapy, relieving patients from the symptoms of SVCS. Therefore, our patient did not require an endovascular stent in the superior vena cava. For less chemotherapy-sensitive tumours often a combination of chemotherapy, radiotherapy and/or endovascular stenting is decided on. ${ }^{12}$ Endovascular stenting provides significant and rapid symptom relief compared with radiotherapy. Thus, this has been proposed as an effective first-line palliative treatment or can be employed when immediate relief of obstruction of the airway or superior vena cava is necessary. ${ }^{4}$ Early recognition and timely diagnosis are crucial in order to alleviate symptoms of obstruction and initiate immediate treatment to prevent life-threatening complications. ${ }^{12}$
Contributors ALN and LW discussed the reporting and design of the manuscript. ALN and LW drafted the manuscript. ALN, HB, JvH and LW critically revised the manuscript for improved intellectual content. ALN, HB, JvH and LW read and gave final approval for the submitted manuscript. ALN, HB, JvH and LW cared for the patient.

Funding The authors have not declared a specific grant for this research from any funding agency in the public, commercial or not-for-profit sectors.

Competing interests None declared.

Patient consent Next of kin consent obtained.

Provenance and peer review Not commissioned; externally peer reviewed.

Author note Informed consent was obtained from the patient (oral approval) and the husband of the patient (signed approval).

(c) BMJ Publishing Group Ltd (unless otherwise stated in the text of the article) 2018. All rights reserved. No commercial use is permitted unless otherwise expressly granted.

\section{REFERENCES}

1 Wilson LD, Detterbeck FC, Yahalom J. Clinical practice. Superior vena cava syndrome with malignant causes. N Eng/ J Med 2007;356:1862-9.

2 Drews RE, Rabkin DJ. Malignancy-related superior vena cava syndrome-UpToDate. http://www.uptodate.com/contents/malignancy-related-superior-vena-cava-syndrome (accessed 15 Feb 2018).

3 Anders H, Keller C. Pemberton's maneuver - a clinical test for latent superior vena cava syndrome caused by a substernal mass. Eur J Med Res 1997;2:488-90.

4 Nicholson AA, Ettles DF, Arnold A, et al. Treatment of malignant superior vena cava obstruction: metal stents or radiation therapy. J Vasc Interv Radiol 1997;8:781-8.

5 Lanciego C, Pangua C, Chacón JI, et al. Endovascular stenting as the first step in the overall management of malignant superior vena cava syndrome. AJR Am J Roentgenol 2009;193:549-58.

Copyright 2018 BMJ Publishing Group. All rights reserved. For permission to reuse any of this content visit

http://group.bmj.com/group/rights-licensing/permissions.

BMJ Case Report Fellows may re-use this article for personal use and teaching without any further permission.

Become a Fellow of BMJ Case Reports today and you can:

- Submit as many cases as you like

- Enjoy fast sympathetic peer review and rapid publication of accepted articles

- Access all the published articles

Re-use any of the published material for personal use and teaching without further permission

For information on Institutional Fellowships contact consortiasales@bmjgroup.com

Visit casereports.bmj.com for more articles like this and to become a Fellow 